\title{
Interaction Design for Online Video and Television
}

\author{
David Geerts \\ CUO | Social Spaces \\ iMinds / KU Leuven \\ Parkstraat 45 Bus 3605 \\ 3000 Leuven, Belgium \\ david.geerts@soc.kuleuven.be \\ Pablo Cesar \\ CWI \\ Kruislaan 413, Amsterdam \\ 1098 SJ, The Netherlands \\ p.s.cesar@cwi.n
}

\begin{abstract}
This course will teach attendees how to design and evaluate interaction with online video and television. It provides attendees a pragmatic toolset, including techniques and guidelines, which can be directly applied in practice. The different tools will be contextualized based on current developments, giving participants a complete overview of the state of the art and industry.
\end{abstract}

\section{Author Keywords}

Interactive TV; online video; interaction design

\section{ACM Classification Keywords}

H5.1 [Information Interfaces and presentation]: Multimedia information systems - audio, video

\section{Content of the Course}

In this course, the instructors will first give an extensive overview of successful existing and emerging television and online video applications, on the web, on television and on smartphones and tablets. Special attention will be paid to current commercial developments in TV offerings, online video, and second screen applications. The instructors will highlight and summarize the most important features present in these applications and present them in a coherent framework. The framework will help in understanding the relevance of these emergent applications for the 
CHI community, in particular which aspects of user experience are relevant for TV and video applications and which interaction design techniques can be of help when designing them. Two example applications will be analysed in more detail, to assess their strengths and weaknesses in depth.

Next, the instructors will provide a detailed overview on the design of online video and television applications that exploit novel features, with an emphasis on social interactivity, interaction techniques and content. The following key principles in designing such applications will be discussed in detail: activity, awareness, synchronization, social interaction, device, and social reach. Each of the principles will be illustrated by using existing design projects, including secondary screens, rich social experiences with other viewers and social sharing of television content with closed relationships. The intention of using these examples is to share the instructors' experiences in designing such applications.

After these key design principles, we will show how TV and online video applications can be evaluated. First we will discuss how usability and sociability can be studied by performing user tests, which aspects of testing are different from studying applications in other domains, and include practical tips on how to improve user testing focused on the user experience of TV and online video. Then we will go over a number of heuristics, based on the design principles discussed earlier, for designing online video and television applications.

In order to better explain the underlying concepts, we will perform a plenary group exercise in which the participants are invited to apply the design principles and heuristics and evaluate and redesign an online video application. Participants will be put in pairs, and a set of screenshots of an application will be handed out to them. They will be given approximately ten minutes for inspecting the interface, identifying user experience problems, and suggesting a redesign. During the next ten minutes, each pair of participants will shortly present one of their key findings, resulting in 10-20 ideas for redesigning the application.

Finally, the instructors will explore the future of the emerging trends in TV and online video and together with the participants discuss what factors can lead to the success or failure of these kinds of applications.

\section{Instructors}

David Geerts has a PhD in Social Sciences at the KU Leuven, Belgium where he is Research Manager of the Centre for User Experience Research. David is specialized in user-centered design and evaluation of social TV and is general chair of ACM TVX2015.

Pablo Cesar has a PhD from Helsinki University of Technology. He leads the Distributed and Interactive Systems group at CWI in the Netherlands. He has (co)authored over 80 conference papers and journal articles about multimedia systems and infrastructures, social media sharing, interactive media, multimedia content modelling, and user interaction. Pablo was program chair of ACM TVX2014 and he is the chair of the steering committee of ACM TVX. 